\title{
В.П. Чудинова
}

\section{Дети, молодежь и взрослые посетители публичных библиотек СIIA в ракурсе Теории поколений В. Штрауса и Н. Хоува*}

Реферат. В последнее десятилетие в обществе активно обсуждается тема нового облика «цифрового» поколения. В США распространена Теория поколений В. Штрауса и Н. Хоува, описывающая образы и основные факторы, влияющие на формирование ценностей поколений. Важное значение имеет детский возраст, когда ценности складываются под влиянием внешних событий, происходящих в обществе, культуры и традиций воспитания в семье. Представлены результаты социологических исследований последних двух «цифровых» поколений детей и молодежи конца XX - начала XXI в., проведенные исследовательскими центрами США на основе данной теории.

В работе американского библиотекаря Л. Фармер приводятся данные относительно информационных и образовательных технологий, которыми пользовались поколения США в последнее столетие. Ею проанализировано, как эти изменения в образовании и информационных технологиях повлияли на работу, роль и задачи американских библиотек. Сегодня важное значение для деятельности библиотекарей и педагогов имеет понимание особенностей новых поколений - детей, подростков и молодежи.

Ключевые слова: дети, подростки, молодежь, Теория поколений В. Штрауса и Н. Хоува, исследования, библиотекари.

Для цитирования: Чудинова В.П. Дети, молодежь и взрослые посетители публичных библиотек США в ракурсе Теории поколений В. Штрауса и Н. Хоува// Библиотековедение. 2017. Т. 66, № 5. С. 553559. DOI: 10.25281/0869-608X-2017-66-5-553-559.

\section{«Дети цифровой эрым: появление первого поколения}

Прежде чем остановиться на исследованиях, проводившихся в рамках Теории поколений В. Штрауса и Н. Хоува в США, отметим, что большой интерес к изменившемуся облику и привычкам детей, подростков и юношества особенно усилился на рубеже веков. В последние десятилетия в СМИ западных стран активно обсуждалась тема нового облика поколения «цифровых» детей, которым давались разные названия ( циирровые аборигены», «поколение Сети», «поколение NEXT» и др.).

Педагоги столкнулись с проблемой изменений в навыках работы с информацией и коммуникацией у подростков и молодежи. Широко приме-

* При написании статьи использованы результаты исследований, выполненные при поддержке Российского гуманитарного научного фонда (РГНФ) в рамках научного проекта № 16-06-00792а.

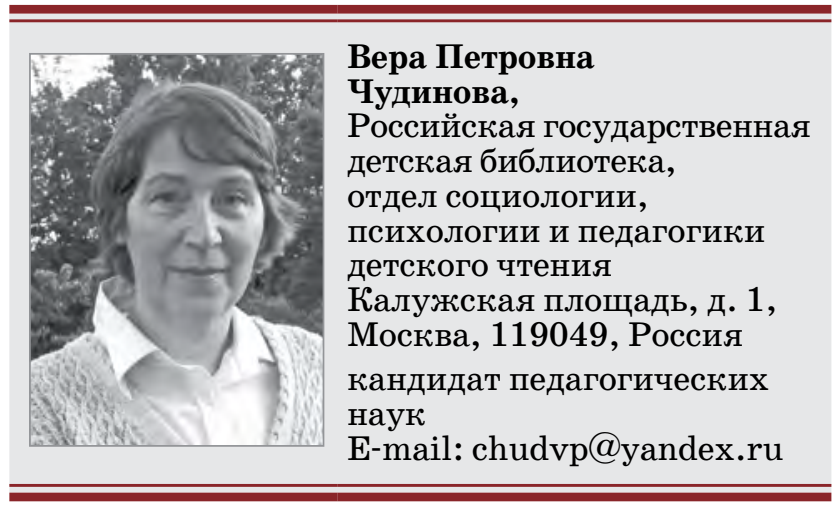

нимым к детям, подросткам, юношам и девушкам на Западе стало новое словосочетание «цифровые аборигены», появившееся в США в 2001 году. Термин был предложен М. Пренски, писателем и популяризатором новых технологий обучения в статье «Цифровые аборигены, цифровые иммигранты» («Digital Natives, Digital Immigrants») [1]. Назва- 
ние было придумано по аналогии со словом native, которое в английском языке означает коренной житель (уроженец, абориген). Таким образом, цифровой человек - это коренной житель цифрового общества или века цифровых технологий.

В 2008 г. в США вышла книга "Дети цифровой эры» («Born digital: Understanding the First generation of Digital Natives»), где исследователями в сфере массовых коммуникаций Дж. Пэлфри и У. Гассером были обобщены результаты различных изысканий облика нового поколения [2]. Здесь также используются термины, характеризующие поколения до и после «Эры Интернета»: «цифровой иммигрант» (Digital immigrant) - человек, который родился до наступления цифровой эпохи, но умеет пользоваться Интернетом и другими цифровыми технологиями; «цифровое поколение» (digital native) - люди, родившиеся в цифровую эру (после 1980 г.), имеющие доступ к цифровым технологиям и обладающие навыками работы на компьютере. С точки зрения данных исследователей, в последнее десятилетие сформировалась общая глобальная культура детей цифровой эры, принадлежность к которой определяется не столько по возрасту, сколько по тому, как пользователи взаимодействуют с самой информацией, с информационными технологиями, друг с другом, а также с иными людьми и организациями.

В 2000-е гг. в западных странах был проведен ряд исследований, значительная часть которых относится к изучению юных представителей этого первого «цифрового» поколения [3].

Однако в наши дни дети первого «цифрового» поколения перешли в другую возрастную категорию и относятся к молодежи. Сегодня большой интерес у исследователей, педагогов и библиотекарей вызывают представители уже второго «цифрового» поколения. Эти дети, подростки, юноши и девушки живут в постоянно расширяющейся информационной вселенной и во многом отличаются от предыдущих поколений $\mathrm{XX}$ в., чье обучение проходило в условиях литературоцентричной культуры. Для библиотекарей как специалистов по работе с информацией важно не только видеть отличия поколений, понимать их особенности, но и представлять условия, повлиявшие на их формирование.

\section{О Теории поколений В. Uтрауса и H. Хоува}

Один из подходов, описывающих социокультурную динамику поколений, сегодня стал особенно популярным в США и за ее пределами. Это теория американских исследователей Вильяма Штрауса и Нейла Хоува (William Strauss, Neil Howe), созданная в 1991 г. [4] (теория подробно описывается в англоязычной Википедии). Ее популярность объясняется, прежде всего, подходом, определяющим значительные изменения в ценностях и привычках современной молодежи в отличие от предыдущих поколений. Результаты исследований, проводимые в рамках этой теории, приобретают большую значимость для работодателей, в том числе, помогают решать проблемы адаптации молодежи к рынку труда, а также ее подготовки к новым профессиям в будущем.

В. Штраус и Н. Хоув определяют социальное поколение как совокупность людей, рожденных в 20-летний промежуток времени и имеющих три общих критерия возрастного положения в истории: переживание тех же основных исторических событий в приблизительно одинаковом возрасте, выработавших похожие ценности. Данные критерии можно рассматривать в качестве основных факторов, влияющих на формирование поколения. Большое внимание в Теории поколений уделяется детству, когда происходит образование ценностей.

Теория поколений изучает два больших блока вопросов: ценности поколений, а также цикличность в событиях и явлениях, влияющих на формирование ценностей. Авторы теории проанализировали историю США и обнаружили определенные периоды, когда большинство людей обладают сходными ценностями. По их мнению, история развивается циклами, продолжительность которых приблизительно равна продолжительности человеческой жизни. Один цикл, длительностью примерно 80 лет (в истории длительность цикла бывает от 75 до 100 лет), образует периоды формирования четырех поколений. По завершении цикла начинается повторение: пятая генерация обладает ценностями, схожими с первой.

Дети, рожденные на стыке генераций, испытывают влияние двух групп ценностей и образуют так называемое переходное или эхо-поколение. Потомки нового цикла во многом повторяют характерные особенности соответствующих поколений предыдущего цикла. Идея смены циклов, чередования в истории периодов спада и подъема, как оказывается, позволяет довольно точно описать облики и периоды изменения поколений, которые, обладая сходным историческим опытом в детстве и юности, живут по похожим жизненным сценариям.

Большой эмпирический опыт, собираемый в разных странах в рамках данного подхода относительно поведения и ценностей последних четырех поколений, свидетельствует о том, что описанные циклы и социодинамика их смены имеют под собой довольно убедительное основание. Подробнее описание данной теории выполнено в работах российских ученых М.А. Исаевой [5] и Ю.В. Асташовой [6], Е. Шамис и Е. Никонов на ее основе проводят свои исследования в России [7; 8]. Критический анализ теории В. Штрауса и Н. Хоува проведен в работе В. Куренного [9]. Он пишет о том, что критики неоднократно отмечали упрощенный характер предложенной ими трактовки проблемы поколений, ее схематизм. С этим мнением исследователя можно согласиться, однако сегодня Теория поколений - один из 
наиболее распространенных подходов в изучении поколенческих циклов в западных странах. Необходимо отметить границы применения этой теории: она относится к представителям среднего класса, и именно это формирует и определяет характеристики того или иного поколения.

Такой подход позволяет исследователям сравнивать влияния на ценности поколений социокультурной среды и деятельность различных социальных институтов, начиная с детского возраста. В проведенных на Западе исследованиях поколений изучаются их ценности (в том числе, влияние на личность человека его религиозной принадлежности), особенности в коммуникации, поведение при использовании новых технологий, отношение к работе, участие в жизни общества (например, в добровольческих организациях) и другие характеристики. Значительное внимание в исследованиях уделено различиям в ценностях поколений, особенностям их облика и поведения, формированию внутрипоколенческой идентичности.

В США после публикации Теории поколений В. Штрауса и Н. Хоува проводилось и продолжает проводиться много изысканий. Крупнейшее социологическое агентство США - Исследовательский центр Пью (Pew Research Center, PRC) - последние 20 лет проводит анализ ценностей и поведения американцев на основе этой теории [10]. Центром изучаются последние живущие в США поколения:

- молчаливое поколение (The Silent generation, 1928-1945 г. р.);

- беби-бумеры (The Baby Boomer, 19461964 г. р.) - послевоенное поколение, когда был бум рождаемости;

- поколение X(X Generation, 1965-1980 г. p.);

- миллениалы или поколение Y (Y-Millennials generation, $1981-2000$ г. p.).

Не исследуется лишь поведение и ценности «величайшего поколения» (The Greatest Generation), - родившихся до 1928 г., тех, кто выиграл Вторую мировую войну, поскольку их осталось уже немного.

\section{Социологические исследования детей и молодежи в США}

В настоящее время исследователями особое внимание уделяется двум последним - «цифровым» поколениям. Много работ посвящено поколе- нию Y или миллениалам (Millennials), т. е. родившимся в 1981-2000 годах [11]. Именно оно сегодня становится основной рабочей силой, движущей общественное развитие в США. В исследованиях использован большой объем вопросов, связанных с характеристиками поколений (их ценности, поведение, использование новых технологий, отношение к работе, религии, гражданскому обществу, в том числе работа в качестве волонтеров и многое другое). Значительное внимание уделяется различиям в ценностях поколений, а также тому, что делает поколение «особенным».

Миллениалы (название этого поколения переводят по-разному - миллениумы, тысячелетние, двухтысячники) - это первое «цифровое» поколение, и именно эту особенность представители сами поставили на первое место. Например, три четверти миллениалов создали собственный профиль в социальной сети, по сравнению с $50 \%$ поколения $\mathrm{X}$, с $30 \%$ бэби-бумеров и всего $6 \%$ поколения молчаливых. У них также наибольшее количество знакомых в социальных сетях.

Это поколение - самое образованное в истории США, каждый третий имеет высшее образование. В современном обществе влияние образования тесно связано с личным доходом и во многом определяет его размер. Но при этом среди данного поколения гораздо больше тех, кто будет платить значительные кредиты за получение высшего образования. Есть и другие отличия. Молодые представители этого поколения значительно позже вступают в брак, чем предыдущие (средний возраст составляет 29 лет для мужчин и 26 лет для женщин), более критичны и значительно менее религиозны. Они также более привержены либеральным ценностям и терпимее к окружающим. Гораздо чаще других поколений играют в видеоигры, самостоятельно размещают в Интернете созданный видеоконтент и полагают, что новые технологии делают жизнь проще и позволяют людям стать ближе друг к другу [12].

Имеются также значительные отличия в использовании этим поколением мобильного телефона (отправление, получение СМС или выход в Интернет) (табл. 1).

В последнее время на Западе стали проводиться исследования нового поколения, подростков, родившихся после 2000 года. Это - представители уже второго «цифрового» поколения с условным названием «поколение $\mathrm{Z}$ » («Gen $\mathrm{Z}$ » или «iGen»).

Таблица 1 Использование различными поколениями мобильного телефона

\begin{tabular}{|l|c|c|c|}
\hline \multicolumn{1}{|c|}{ период } & миллениалы & поколение Х & беби-бумеры \\
\hline $\begin{array}{l}\text { во время семейного } \\
\text { обеда }\end{array}$ & $31 \%$ & $28 \%$ & $20 \%$ \\
$\begin{array}{l}\text { во время урока или } \\
\text { лекции }\end{array}$ & $22 \%$ & $16 \%$ & $12 \%$ \\
\hline $\begin{array}{l}\text { в церкви или во время } \\
\text { церковной церемонии } \\
\text { на деловой встрече }\end{array}$ & $12 \%$ & $12 \%$ & $5 \%$ \\
\hline
\end{tabular}

Название пока не устоялось, и используются различные варианты, такие как «постмиллениалы», «линкстеры» и др. [13]. Отмечаются такие характеристики поколения, как «связанность» (они все время на связи) и многозадачность (могут использовать несколько экранов и видов устройств одновременно). Важен и возраст приобретения смартфона, который позволяет делать практи- 
чески все: общаться со сверстниками, работать онлайн, играть в видеоигры, пользоваться социальными сетями, искать информацию в Интернете и получать доступ к миру новостей, а также к развлечениям. Сегодня наличие собственного смартфона - это не просто символ статуса (что было характерно для многих millennials), это жизненная потребность юных, поскольку цена смартфонов значительно снизилась, а их доступность увеличилась. Оказалось, что подростки, юноши и девушки считают, что оптимальный возраст его получения, это 13 лет, тогда как более старшие поколения отмечают возраст 18 лет. Одна из отличительных особенностей этого поколения: $42 \%$ его молодых представителей говорит о том, что социальные медиа имеют прямое влияние на их самочувствие [14].

Изучаются не только подростки, но и самые младшие представители этого поколения - маленькие дети, которые легко используют приложения с сенсорными экранами. Сегодня специалисты в области образования решают в США, как использовать айпады, которыми охотно пользуются маленькие дети, в целях образования [15].

\section{Поколения и библиотеки в контексте перемен в образовании}

Исследование PRC, проведенное осенью 2016 г., показывает, что 53\% миллениалов (в возрасте от 18 до 35 лет) утверждают, что в течение последних 12 месяцев они пользовались услугами библиотеки или библиомобиля, тогда как представители более старших поколений реже посещают библиотеки. Так, в этот период их посещали только 45\% представителей поколения Х, 43\% представителей бэби-бумеров и $36 \%$ представителей молчаливого поколения.

Молодые представители поколения миллениалов чаще посещают и сайты библиотек. Например, в 2016 г. 41\% миллениалов посещали сайт библиотеки по сравнению с $33 \%$ поколения $\mathrm{X}$, $24 \%$ поколения бэби-бумеров и $11 \%$ представителей молчаливого поколения. Относительно высокое использование библиотеки миллениалами, возможно, связано с изменениями, происходившими в американских библиотеках за последние 20 лет: оснащение новой техникой, широкое использование посетителями компьютеров и Интернета, заинтересованность в различных дополнительных услугах библиотек [16]. Среди таких услуг: программы улучшения уровня грамотности у различных категорий пользователей библиотек, организация встреч групп местного сообщества, использование новых технологий и электронных устройств (например, 3D-принтеров) и др. [17].

Используя подходы данной теории, библиотекари стремятся понять особенности облика, поведения и коммуникации разных поколений. Американский библиотекарь - исследователь и педагог Л. Фармер описала поколения и роль библиотек в контексте реформ образования в США (табл. 2) [18]. В таблице, приведенной Л. Фармер, при описании новых технологий использован ряд сокращений. Например, PDA (Personal Digital Assistants персональные цифровые помощники); камкодеры - устройства, сочетающие функции камеры и видеопроигрывателя; iPOd (цифровой аудиоплеep), GIS (ГИС - географическая информационная система).

Из данных этой таблицы наглядно видно, как за последнее столетие значительно изменились информационные и образовательные технологии, которыми пользовались поколения американцев XX - начала XXI в., и как менялись в связи с этим функции и задачи библиотек. Библиотекари США традиционно играют значительную роль в образовании и просвещении американского населения. Вместе с тем они становятся навигаторами в меняющемся информационном пространстве. При этом их задачи многократно усложнились, особенно в связи с изменениями в поведении новых «цифровых» поколений, прежде всего детей, подростков, юношей и девушек.

Библиотекарям необходимо учитывать значительные различия при работе с новыми ИКТ и объемом информации у разных поколений. Л. Фармер обращает внимание также на то обстоятельство, что американские библиотекари четко определяют свои задачи в качестве просветителей и неформальных учителей, помогающих гражданам страны стать более грамотными. При этом понятие грамотности значительно расширилось и трансформировалось, что ставит новые задачи перед библиотекарями. В то же время поддержка чтения и читательской грамотности остается одной из приоритетных задач библиотекарей.

Сегодня особенно важно учитывать сходство и отличие поколений, поскольку первые два «цифровых» поколения во многом отличаются от предыдущих, прежде всего, при использовании ими новых информационных технологий. Это обстоятельство ставит вопросы относительно их взаимопонимания и эффективного взаимодействия.

Общение детей и подростков как представителей поколения Z с представителями поколений бэби-бумеров и поколения Х становится довольно сложным. В то же время именно эти, более старшие поколения составляют основу персонала публичных и школьных библиотек. В результате многие библиотекари старшего возраста говорят о том, что дети и подростки, юноши и девушки «другие» и что они значительно отличаются от предыдущих поколений (опираясь на воспоминания своего детства и юности).

Л. Фармер подчеркивает, что при оценке и вариантах действий в той или иной сложившейся ситуации неодинаковые поколения считают правильными разного рода методы, решения, описывают их иным языком, делают акцент на различных деталях, что иногда приводит к взаимному недо- 
Роль и задачи библиотекарей в контексте перемен в образовании [18]

\begin{tabular}{|c|c|c|c|c|c|}
\hline Поколение & $\begin{array}{c}\text { Форматы } \\
\text { информации }\end{array}$ & $\begin{array}{c}\text { Образовательные } \\
\text { технологии }\end{array}$ & $\begin{array}{c}\text { Тенденции } \\
\text { и проблемы } \\
\text { образования }\end{array}$ & Роль библиотек & Грамотность \\
\hline $\begin{array}{l}\text { Традициона- } \\
\text { листы/ } \\
\text { («Молчаливое } \\
\text { поколение») / } \\
\text { зрелые люди, } \\
\text { рожденные до } \\
1943 \text { г. }\end{array}$ & $\begin{array}{l}\text { Печатная, } \\
\text { микроформы, } \\
\text { средства } \\
\text { массовой } \\
\text { информации } \\
\text { (радио, ТВ, } \\
\text { аудиозаписи) }\end{array}$ & $\begin{array}{l}\text { Радио, фильмы, } \\
\text { микрофильмы, } \\
\text { слайды, } \\
\text { диафильмы, } \\
\text { аудиозаписи }\end{array}$ & $\begin{array}{l}\text { Лекции; } \\
\text { учебники; } \\
\text { сегрегация }\end{array}$ & $\begin{array}{l}\text { Хранилища; } \\
\text { народные } \\
\text { университеты } \\
\text { (автодидактика); } \\
\text { обслуживание } \\
\text { детей }\end{array}$ & $\begin{array}{l}\text { Чтение и письмо; } \\
\text { арифметические } \\
\text { навыки }\end{array}$ \\
\hline $\begin{array}{l}\text { Поколение } \\
\text { беби-бума: } \\
\text { рожденные } \\
\text { в } 1946- \\
1965 \text { гг. }\end{array}$ & $\begin{array}{l}\text { Вышеуказанное } \\
\text { плюс ТВ, } \\
\text { аудиозаписи }\end{array}$ & $\begin{array}{l}\text { «Большие» ЭВМ, } \\
\text { транзисторы, } \\
\text { проигрывате- } \\
\text { ли, фотокопи- } \\
\text { ровальные } \\
\text { устройства }\end{array}$ & $\begin{array}{l}\text { GI Bill } \\
\text { (Армейский } \\
\text { билль о правах } \\
1944 \text { г.) } \\
\text { програм- } \\
\text { мное обучение; } \\
\text { гражданские } \\
\text { права; открытое } \\
\text { образование }\end{array}$ & $\begin{array}{l}\text { Использование } \\
\text { аудиовизуальных } \\
\text { материалов; } \\
\text { библиобусы; } \\
\text { цензура; } \\
\text { маккартистская } \\
\text { культура }\end{array}$ & $\begin{array}{l}\text { Вышеуказанное } \\
\text { и фонетическая } \\
\text { грамотность; } \\
\text { математиче- } \\
\text { ская и научная } \\
\text { грамотность }\end{array}$ \\
\hline $\begin{array}{l}\text { Поколение X: } \\
\text { рожденные } \\
\text { в } 1966 \text { - } \\
1980 \text { гг. }\end{array}$ & $\begin{array}{l}\text { Вышеуказанное } \\
\text { и видео-, } \\
\text { цифровой } \\
\text { формат } \\
\text { (оптические } \\
\text { диски, ПО, } \\
\text { рождение } \\
\text { Интернета) }\end{array}$ & $\begin{array}{l}\text { ПК, видео, } \\
\text { калькуляторы, } \\
\text { появление } \\
\text { обучающих } \\
\text { программ, } \\
\text { лазерные диски, } \\
\text { видеоигры, } \\
\text { возникновение } \\
\text { Интернета }\end{array}$ & $\begin{array}{l}\text { Равноправие } \\
\text { (напр., Title } \\
\text { IX, Public Law } \\
94-142, \text { Title I, } \\
\text { ESEA); «назад } \\
\text { к основам» }\end{array}$ & $\begin{array}{l}\text { Закон } 1964 \text { г. } \\
\text { о библиотечном } \\
\text { обслуживании } \\
\text { и строитель- } \\
\text { стве обеспечил } \\
\text { поддержку прежде } \\
\text { неохвачен- } \\
\text { ных групп; } \\
\text { обслуживание } \\
\text { юношества; } \\
\text { библиографическое } \\
\text { обучение }\end{array}$ & $\begin{array}{l}\text { Медийная } \\
\text { грамотность; } \\
\text { визуальная } \\
\text { грамотность; } \\
\text { обучение чтению } \\
\text { методом целых } \\
\text { слов; процессы } \\
\text { письма }\end{array}$ \\
\hline $\begin{array}{l}\text { Поколение } \\
\text { Миллениума: } \\
\text { рожденные } \\
\text { в } 1981- \\
2000 \text { гг. }\end{array}$ & $\begin{array}{l}\text { Вышеуказанное } \\
\text { и виртуальная } \\
\text { реальность, } \\
\text { мобильные } \\
\text { цифровые } \\
\text { устройства }\end{array}$ & $\begin{array}{l}\text { CD, World Wide } \\
\text { Web, PDA-g } \\
\text { персональные } \\
\text { помощники, } \\
\text { цифровые } \\
\text { фотоаппараты / } \\
\text { камкодеры }\end{array}$ & $\begin{array}{l}\text { Федераль- } \\
\text { ный закон } \\
2001 \text { г. NCLB: } \\
\text { применение } \\
\text { стандартов, } \\
\text { конструк- } \\
\text { тивизм, } \\
\text { мультикуль- } \\
\text { турализм, } \\
\text { техноло- } \\
\text { гичность }\end{array}$ & $\begin{array}{l}\text { Семейная } \\
\text { грамотность; } \\
\text { обучение } \\
\text { информационной } \\
\text { грамотности }\end{array}$ & $\begin{array}{l}\text { Информационная } \\
\text { грамотность; } \\
\text { технологическая } \\
\text { грамотность; } \\
\text { сбалансированное } \\
\text { чтение }\end{array}$ \\
\hline $\begin{array}{l}\text { Поколение Z: } \\
\text { рожденные } \\
\text { после } 2000 \text { г. }\end{array}$ & $\begin{array}{l}\text { Вышеуказанное } \\
\text { и Веб.2.0, } \\
\text { «мэшап», } \\
\text { приложения, } \\
\text { дополненная } \\
\text { реальность }\end{array}$ & $\begin{array}{l}\text { Веб 2.0, DVD, } \\
\text { iPOd, GIS }\end{array}$ & $\begin{array}{l}\text { Применение } \\
\text { стандартов; } \\
\text { исследо- } \\
\text { вательское } \\
\text { обучение; } \\
\text { чартерные } \\
\text { школы } \\
\text { и образова- } \\
\text { тельные } \\
\text { ваучеры }\end{array}$ & $\begin{array}{l}\text { Интернет- } \\
\text { услуги; игры; } \\
\text { интерактивное } \\
\text { обслуживание }\end{array}$ & $\begin{array}{l}\text { Навыки } \\
\text { XXI в.; цифровое } \\
\text { гражданское } \\
\text { общество; } \\
\text { двухступен- } \\
\text { чатое чтение }\end{array}$ \\
\hline
\end{tabular}

пониманию и острым дискуссиям между ними. Таким образом, библиотекарям необходимо учитывать особенности всяких поколений, чтобы облегчить коммуникацию между ними.

Результаты исследований, проводимые в США на основе Теории поколений В. Штрауса и Н. Хоува, во многом позволяют лучше понять особенности поколений, выросших в разной культурной и информационной среде, а их знание важно по многим причинам. Оно необходимо не только для улучшения коммуникации, поддержки межгенерационной связи, но также очень важно для сохранения культуры и культурной преемственности поколений, что остается одной из главных задач библиотекарей. 


\section{Список источников}

1. Prensky M. Digital Natives, Digital Immigrants [Электронный ресурc]. URL: http://www.marcprensky. com/writing/Prensky\% 20-\% 20Digital\% 20 Natives, \% 20Digital\% 20Immigrants \% 20-\% 20 Part1. pdf (дата обращения: 17.03.2017).

2. Пэлфри Дж., Гассер У. Дети цифровой эры / [пер. с англ. Н.Г. Яцюк]. Москва : Эксмо, 2011. 368 с.

3. Носова С.С., Кужелева-Саган И.П. Молодежь в сетевом информационно-коммуникативном обществе: зарубежные подходы к изучению проблемы [Электронный ресурс]. URL: https://cyberleninka. $\mathrm{ru} / \operatorname{article} / \mathrm{n} /$ molodezh-v-setevom-informatsionnokommunikativnom-obschestve-zarubezhnyepodhody-k-izucheniyu-problemy (дата обращения: 10.08.2017).

4. Strauss W., Howe N. The Fourth Turning: An American Prophecy - What the Cycles of History Tell Us About America's Next Rendezvous with Destiny. New York : Broadway Books, 1997. 400 p.

5. Исаева М.A. Поколения кризиса и подъема в теории В. Штрауса и Н. Хоува // Знание. Понимание. Умение. 2011. № 3. С. 290-295.

6. Асташова Ю.В. Теория поколений в маркетинге // Вестник Южно-Уральского гос. ун-та. Серия «Экономика и менеджмент». 2014. Т. 8. Вып. № 1. C. $108-114$.

7. Шалис E. Теория поколений в России [Электронный pecypc]. URL: http://rugenerations.su (дата обращения: 03.05.2017).

8. Шалис E., Никонов E. Теория поколений: необыкновенный Икс. 2-е изд., стер. Москва : Ун-т «Синергия», 2017. 140 с.

9. Куренной В. Кто такие миллениалы? Культуролог Виталий Куренной о теории поколений, «эхо-бумерах» и фазах поколенческих «превращений» [Электронный ресурс]. URL: https://postnauka. $\mathrm{ru} / \mathrm{faq} / 62552$ (дата обращения: 05.08.2017).

10. Social \& Demographic Trends. Generations and Age [Электронный ресурс] // Pew Research Center. URL: http://www.pewsocialtrends.org/topics/generationsand-age/ (дата обращения: 20.05.2017).

11. Comparing Millennials to Other Generations [Электронный pecypc] // Pew Research Center. URL: http://www.pewsocialtrends.org/2015/03/19/ comparing-millennials-to-other-generations/ (дата обращения: 20.05.2017).

12. Millennials: Confident. Connected. Open to Change [Электронный ресурс] // Pew Research Center. URL: http://www.pewsocialtrends.org/2010/02/24/millennials-confident-connected-open-to-change/\#whats-ina-name (дата обращения: 15.04.2017).

13. Что нужно знать о поколении Z. О мировоззрении, поведении и увлечениях постмиллениалов [Электронный ресурс]. URL: https://www.buro247. ru/lifestyle/obshcestvo/24-jul-2017-all-aboutgeneration-z.html (дата обращения: 08.08.2017).

14. CGK. The Center for Generational Kinetics. Gen Z: New Research and Findings on the Generation After Millennials [Электронный pecypc]. URL: http:// genhq.com/gen-z/ (дата обращения: 15.05.2017).

15. Малыш и айпад [Электронный ресурс] // Дети в информационном обществе. 2014. № 17. URL: http://detionline.com/journal/numbers/17/ (дата обращения: 15.05.2017).

16. Millennials are the most likely generation of Americans to use public libraries [Электронный pecypc] // Pew Research Center URL: http://www.pewresearch. org/fact-tank/2017/06/21/millennials-are-the-mostlikely-generation-of-americans-to-use-public-libraries/ (дата обращения: 05.08.2017).

17. Horrigan J.B. Libraries at the Crossroads. The public is interested in new services and thinks libraries are important to communities [Электронный pecypc]. URL: http://www.pewinternet.org/2015/09/15/librariesat-the-crossroads/ (дата обращения: 05.08.2017).

18. Фармер Л. Обзор библиотечного обслуживания детей и юношества в США // Библиотечное обслуживание молодежи в Японии, России и США. Серия 1. Вып. 3-4. Москва : Русская школьная библ. ассоц., 2013. C. $243-265$.

\title{
Children, Young Adults and Adult Visitors of the Public Libraries of the United States in terms of the Strauss-Howe Generational Theory
}

\author{
Vera P. Chudinova, \\ Russian State Children's Library, 1 Kaluzhskaya Square, Moscow, 119049, Russia \\ E-mail: chudvp@yandex.ru
}

\begin{abstract}
In the last decade in society, the topic of new image of the "digital" generation is being actively discussed. In the USA there is widespread the Strauss - Howe generational theory, describing the images and the main factors that influence the formation of the values of generations. It is highlighted the importance of the children's age, when values are formed under the influence of external events occurring in society, as well as the culture and traditions of upbringing in family. There are presented the results of
\end{abstract}


sociological studies of the two recent "digital generations" of children and young people of the late twentieth - early twenty first century, conducted by the research centres in the United States on the basis of this theory.

In the work of the American librarian L. Farmer there are provided data on the information and educational technologies that the U.S. generations used in the last century. The researcher analysed how the changes in the educational and information technologies have influenced the work, mission and objectives of the American libraries. Today, special importance for the work of librarians and teachers has the understanding of specific features of the new generations - children, teenagers and young adults.

Key words: Children, Teenagers, Young Adults, Strauss-Howe Generational Theory in the United States, Research, Librarians.

Citation: Chudinova V.P. Children, Young Adults and Adult Visitors of the Public Libraries of the United States in terms of the Strauss - Howe Generational Theory, Bibliotekovedenie [Library and Information Science], 2017, vol. 66, no. 5, pp. 553-559. DOI: 10.25281/0869-608X-2017-66-5-553-559.

Acknowledgements: The article uses the results of the research conducted at the support of the Russian Humanitarian Science Foundation (RHSF) under the scientific project No. 16-06-00792a.

\section{References}

1. Prensky M. Digital Natives, Digital Immigrants. Available at: http://www.marcprensky.com/writing/ Prensky \% 20-\% 20Digital \% 20Natives, \% 20Digital $\% 20$ Immigrants \% 20-\% 20Part1.pdf (accessed 17.03.2017).

2. Palfrey J., Gasser U. Born Digital: Understanding the First Generation of Digital Natives. Moscow, Eksmo Publ., 2011, 368 p. (in Russ.).

3. Nosova S.S., Kuzheleva-Sagan I.P. Molodezh'v setevom informatsionno-kommunikativnom obshchestve: zarubezhnye podkhody kizucheniyu problemy [Young People in the Network Information and Communication Society: Foreign Approaches to the Study of the Problem]. Available at: https://cyberleninka. $\mathrm{ru} /$ article/n/molodezh-v-setevom-informatsionnokommunikativnom-obschestve-zarubezhnye-podhodyk-izucheniyu-problemy (accessed 10.08.2017).

4. Strauss W., Howe N. The Fourth Turning: An American Prophecy - What the Cycles of History Tell Us About America's Next Rendezvous with Destiny. New York, Broadway Books Publ., 1997, 400 p.

5. Isaeva M.A. Pokoleniya krizisa i pod' 'ema v teorii V. Shtrausa i N. Khouva [Crisis and Rise Generations in W. Strauss and N. Howe's Theory], Znanie. Ponimanie. Umenie [Knowledge. Understanding. Skill], 2011, no. 3, pp. 290-295.

6. Astashova Yu.V. Teoriya pokolenii v marketinge [The Theory of Generations in Marketing], Vestnik YuzhnoUral'skogo gos. un-ta. Seriya “Ekonomika i menedzhment" [Bulletin of the South Ural State University. Series "Economics and Management"], 2014, vol. 8, issue 1, pp. 108-114.

7. Shamis E. Teoriya pokolenii $v$ Rossii [The Theory of Generations in Russia]. Available at: http:// rugenerations.su (accessed 03.05.2017).

8. Shamis E., Nikonov E. Teoriya pokolenii: neobyknovennyi Iks [The Theory of Generations: The Extraordinary X]. Moscow, Universitet "Sinergiya” Publ., 2017, 140 p.

9. Kurennoi V. Kto takie millenialy? Kul'turolog Vitalii Kurennoi o teorii pokolenii, "ekho-bumerakh" i fazakh pokolencheskikh "prevrashchenii" [Who Are the Millenials? Culturologist Vitaly Kurennoy - About the Theory of Generations, "Echo-Boomers" and Phases of Generational "Transformations"]. Available at: https://postnauka.ru/faq/62552 (accessed 05.08.2017).
10. Social \& Demographic Trends. Generations and Age, Pew Research Center. Available at: http://www. pewsocialtrends.org/topics/generations-and-age/ (accessed 20.05.2017).

11. Comparing Millennials to Other Generations, Pew Research Center. Available at: http://www. pewsocialtrends.org/2015/03/19/comparing-millennials-to-other-generations/ (accessed 20.05.2017).

12. Millennials: Confident. Connected. Open to Change, Pew Research Center. Available at: http://www. pewsocialtrends.org/2010/02/24/millennialsconfident-connected-open-to-change/\# whats-in-aname (accessed 15.04.2017).

13. Chto nuzhno znat' o pokolenii Z. O mirovozzrenii, povedenii i uvlecheniyakh postmillenialov [What Do You Need to Know about the Z Generation? About the Hobbies, Behavior and Worldviews of Post-Millennials]. Available at: https://www.buro247.ru/lifestyle/ obshcestvo/24-jul-2017-all-about-generation-z.html (accessed 08.08.2017).

14. CGK. The Center for Generational Kinetics. Gen Z: New Research and Findings on the Generation After Millennials. Available at: http://genhq.com/gen-z/ (accessed 15.05.2017).

15. Malysh i aipad [The Baby and the iPad], Deti $v$ informatsionnom obshchestve [Children in the Information Society], 2014, no. 17. Available at: http://detionline. com/journal/numbers/17/ (accessed 15.05.2017).

16. Millennials are the most likely generation of Americans to use public libraries, Pew Research Center. Available at: http://www.pewresearch.org/facttank/2017/06/21/millennials-are-the-most-likelygeneration-of-americans-to-use-public-libraries / (accessed 05.08.2017).

17. Horrigan J.B. Libraries at the Crossroads. The public is interested in new services and thinks libraries are important to communities. Available at: http:// www.pewinternet.org/2015/09/15/libraries-at-thecrossroads / (accessed 05.08.2017).

18. Farmer L. Overview of Youth-Serving Libraries in the United States, Youth-Serving Libraries in Japan, Russia, and the United States, series 1, issues 3-4. Moscow, Russkaya Shkol'naya Bibliotechnaya Assotsiatsiya Publ., 2013, pp. 243-265 (in Russ.). 